\title{
A Furniture Design Guideline Derived from the Socio-Economic Factors of Consumers for Their Choices of Sustainable Furniture Design in Thailand
}

\author{
Karuna Kwangsawat ${ }^{1}$ \& Yanin Rugwongwan ${ }^{1}$ \\ ${ }^{1}$ Faculty of Architecture, King Mongkut's Institute of Technology Ladkrabang (KMITL), Thailand \\ Correspondence: Karuna Kwangsawat. E-mail: Kwangsawath@yahoo.com
}

Received: October 12, $2017 \quad$ Accepted: October 31, $2017 \quad$ Online Published: November 28, 2017

doi:10.5539/ass.v13n12p182 URL: https://doi.org/10.5539/ass.v13n12p182

\begin{abstract}
This article presents an environmentally friendly furniture design guideline which comes from different socio-economic conditions, including personality and physical residence of consumers in Thailand, and is a test for the perception of environmentally friendly furniture style, in order to find the style of environmentally friendly furniture in consumers with different economic backgrounds and perception of the environment. The research found that the needs for the style of environmentally friendly furniture according to different socio-economic conditions were in the same direction, which means that consumers need modern environmentally friendly furniture in western style, using natural materials in manufacturing with high technology, and furniture color in a cool shade. Therefore, the designer should consider the different socio-economic conditions of consumers that affect the needs differently, and use this as a furniture design guideline that is environmentally friendly and appropriate for the needs of consumers.
\end{abstract}

Keywords: Furniture Design, Sustainable Furniture Design, Consumers’ Socio-Economic

\section{Introduction}

\subsection{Introduce the Problem}

At present, businesses cannot operate without considering the environment. Environmental activities and the Green market are applied in business strategy plans and considered top priority in terms of business planning (Durmaz \& Yasar, 2016 ). Thailand has many environmental management policies. Focus on the solution to the manufacturer (Thailandindustry, 2009). For environmentally friendly products in Thailand, SME entrepreneurs in the consumer products business sector, such as Life style furniture, home decoration, containers, textile materials, and others, are encouraged to develop products for exporting into foreign markets so that the SME entrepreneurs can gain the knowledge of creative product design for the environment in the concept of Life Cycle Design, to reduce the impact on the environment systematically and reach maximum performance (Tcdc, 2017). In Thailand, the furniture industry is an industry that receives support and encouragement in terms of quality for the Thai market and exports (SMEs, 2014) but still lacks development in terms of new designs that are acceptable in both the Thai and World markets, and in terms of the use of materials and appropriate manufacturing processes, and the ability of blending materials for the manufacturing (Zhang \& Zhang, 2012) of the furniture according to the popularity of each era, which are the overlapping problems in terms of technological capability, lack of skilled labor force, and having low manufacturing technology. Therefore, the design needs to be developed in order to have more efficacy.

Subsequently, Design for Environment (DfE) is used in the design process, which is very important for product design and is adjusted to be more enforcing for product management (Telenko, Seepersad, \& Webber, 2008) and services in terms of the environment, especially in Northern Europe countries, Japan, and the United States that use it as product rules. Some companies have applied the concept in the design and product improvement process and this group of companies have become the highly competitive market leaders (Brezet \& Hemel, 1997) who are able to design according to the green consumer and the market's needs. At present, emphasis has been placed on the Green market by which consumers can demand for the manufacturer to care for the environment. The importance of buying products and services that minimize environmental impact. Manufacturer and entrepreneur must pay attention to the green consumer. There are many factors that affect consumer buying behavior include demographics, self- concept, knowledge and values. The most influential factors are: demographic or the social-economic of consumers include gen, age, education, occupation and income (Consultants of Technology Co., 2556). The difference in the consumer's socio-economic background is a factor that can set the requirements in terms of furniture style that is appropriate and responds to the needs of consumers (Lewis, Gertsakis, Grant, Morelli, \& Sweatman, 2001). This article points out the differences in the socio-economic factor, including the personality and physical residence of consumers in the context of Thailand that affects the needs for the style of the environmentally friendly furniture, so that the designer can use them as a guideline or policy and develop environmentally friendly furniture that responds to the needs in the consumer market and the furniture is less impact on the environment. (Brown, Hanson, Liverman , \& Merideth Jr., 
1987)

\section{Theoretical Framework}

The research is based on the foundation of sustainability in the environment to be the guideline for sustainable consumption and manufacturing (Lewis, Gertsakis, Grant, Morelli, \& Sweatman, 2001). The principle of this research is furniture design for the environment by focusing on the furniture's design. The objective is to create a process and design guideline for sustainable products for manufacturers and users to be aware of when choosing to use and produce such products that will reduce environmental impact in the manufacturing process of furniture.

\subsection{Design for the Environment Relevant to Furniture}

The furniture industry is placing more importance on the environment by emphasizing the manufacturing process. The furniture industry for offices is an industry where both designers and factory managers are becoming more aware of the environmental impact caused by the manufacturing (Araji \& Shakour, 2013). There are 2 significant elements of design that are relevant to furniture, which are the function and the objective of the design for the environment, by which the furniture must be able to be manufactured and used, and respond to market demand. The main principle of design for the environment must be considered throughout the life cycle of the products in all design processes to ensure that it can reduce environmental problems and lead to the elimination or reduction of the most severe environmental problems (Cole, Elliott, \& Wu, 2008).

Table 1. The Principle of Environmentally Friendly Furniture Design

\begin{tabular}{|c|c|}
\hline Issue & Description \\
\hline $\begin{array}{l}\text { 1. Material Selection } \\
\text { Environmentally friendly materials should be } \\
\text { selected. There are methods for recycling or } \\
\text { consistent with disassembly to reduce the } \\
\text { amount of material to a minimum with } \\
\text { emphasis on function and for usability to } \\
\text { remain and for the quality of the aesthetics or } \\
\text { standards to be applied (Hayles, 2015), as } \\
\text { follows: }\end{array}$ & $\begin{array}{l}\text { - Contains recyclable materials. } \\
\text { - Does not cause toxins or hazards. } \\
\text { - From renewable sources. } \\
\text { - Can be recycled easily. } \\
\text { - Low power consumption. } \\
\text { - Does not cause indoor air quality to be toxic or Sick building syndrome. } \\
\text { - No ozone depletion. } \\
\text { - Reduces a variety of material types and easy to recycle. } \\
\text {-No potential color, texture, or visible object is obscured. Key points from using recycled } \\
\text { materials. } \\
\text {-Use sustainable managed forest materials. }\end{array}$ \\
\hline $\begin{array}{l}\text { 2.Production } \\
\text { Maximizing productivity and minimizing } \\
\text { impact:(COLE, ELLIOTT, \& WU, 2008) }\end{array}$ & $\begin{array}{l}\text {-Reduce the number of components and components. } \\
\text {-Removal and reduction of gemstones. Minimal waste material. } \\
\text { - Reduce the variety of material types. } \\
\text {-Include functional functions together to reduce the hassle and number of components. } \\
\text { - Use low impact materials and use clean production processes. } \\
\text { - Avoid the use of adhesives that require solvent coatings and additives containing heavy } \\
\text { metals. }\end{array}$ \\
\hline $\begin{array}{l}\text { 3.Use } \\
\text { Normally, usage has low environmental } \\
\text { impact. However, the following should be } \\
\text { considered: }\end{array}$ & $\begin{array}{l}\text { - Pay attention to the materials and quality, feel, color, touch, surface design. } \\
\text {-Innovative and a healthy work area that is good for the workplace. } \\
\text {-Furniture must be easy to modify and durable. } \\
\text { - Not obsolete and must be disposed of with no service life. } \\
\text {-Most important is danger to human health, which involves the release of chemicals such } \\
\text { as formaldehyde. Nitrogen dioxide Chlorofluorocarbons (CFCs) and volatile organic } \\
\text { compounds (VOCs) are another form of air pollution (off-gassing), which affects health } \\
\text { and affects the effectiveness of poor employee performance. }\end{array}$ \\
\hline $\begin{array}{l}\text { 4. Avoiding waste and reusing resources. } \\
\text { The problems that arise during production and } \\
\text { disposal are disposal procedures or end of life. } \\
\text { The remains of furniture are a major issue that } \\
\text { results in the amount of furniture that needs to } \\
\text { be buried or the coating and the decoration of } \\
\text { heavy metal as a component. It causes } \\
\text { contamination around landfills, and there is } \\
\text { also the cost of energy and energy transfer } \\
\text { from moving the furniture to the landfill, so } \\
\text { reusable materials should be selected or sent } \\
\text { through a new process. Durable material is } \\
\text { easier to recycle (Hayles, 2015) and is a way } \\
\text { to pull a product out of the waste cycle. The } \\
\text { importance of the purpose of eco-economic }\end{array}$ & $\begin{array}{l}\text { 4.1 Design for durability can be increased by } \\
\text { - Identifying and eliminating key weaknesses in the design, especially the parts for use. } \\
\text { - The design must be compatible with normal conditions and misuse. } \\
\text { - Can be easily repaired or serviced. } \\
\text { - Product design should be upgraded. (upgradability) } \\
\text { 4.2 Design to disassemble } \\
\text { Remember to make the material easy to separate into parts for recycling and reparable and } \\
\text { upgradable to new ones. } \\
\text { - The number of components that are the least fragmented. } \\
\text { - Avoid glue. Use metal clamps and screws by method of push, hook, bolt snap fit (Click). } \\
\text { - Tighten with materials that are compatible with parts. Connected Points and items easily } \\
\text { accessible Removable hand } \\
\text {-Block Design }\end{array}$ \\
\hline
\end{tabular}


design is a design for durability, design for disassembly, design for bruising and regeneration, design for recycling, and safe disposal design (Lewis, Gertsakis, Grant, Morelli, \& Sweatman, 2001)
-In-mold identification on resin parts to distinguish plastics (from ISO 11469 (ISO 2000)

- the minimum material type.

- Components that can't be recycled are easy to remove and dispose.

- The highest priced parts are easily accessible.

- Removing and assembling can be done with simple tools. This makes removing and assembling the smallest possible.

- Parts get as standard as you can.

-Fix in and fastener. Easy to separate pieces to avoid damage.

4.3 Design for Reproduction and Reproduction

The low environmental impact is mostly a reusable product, which must be considered, as well as the life cycle in the design process. The following should be done:

- The product must be robust, resistant to service and service, transport, assembly and disassembly. Worth the repair.

4.4 Design for Material Recycling

A second product can be used.

- Use the least amount of material types and only 2-3 types, although the volume is high because it can be recycled better than using 4-5 types, but less.

- There should be a code or symbol that can identify the type of material.

- When disassembled, should be separated to be same kind. Identify species for fast, safe, unmixed.

- Avoid contamination of metal in plastic.

- Avoid using laminate and composite materials.

- Use a tensile strap to prevent contamination of cross-type materials.

- Avoid using adhesive that is different from the material to be welded together to avoid contamination.

- Choose duplicate materials at every stage of design as possible.

4.5 Safe disposal design

Observe label precautions for disposal. How to bind gas contaminants or identify toxic substances. Include contact information for safe disposal. The most important thing is not to use substances or ingredients that cause pollution problems.

\subsection{Integrated Care and Recovery}

Manufacturers must emphasize environmental policies and regulations. The current is more concentrated. The manufacturer must remove the product. At the end of its useful life, must be called back to eliminate. Responsibility is more than sales of showroom. Warranty and service agreement product stewardship and extended product responsibility for such a method is called "product take-back" (Chiu \& Chu, 2012).

\subsection{Research Questions and Hypotheses}

According to the research objective, the significant research questions are; (a) How do consumers with different personalities have different needs in terms of the style of the environmentally friendly furniture? (b) How do consumers with different physical residence have different needs in terms of the style of the environmentally friendly furniture? The independent variables and dependent variables are shown in the below figure:

\section{INDEPENDENT VARIABLES INDEPENDENT VARIABLES DEPENDENT VARIABLES}

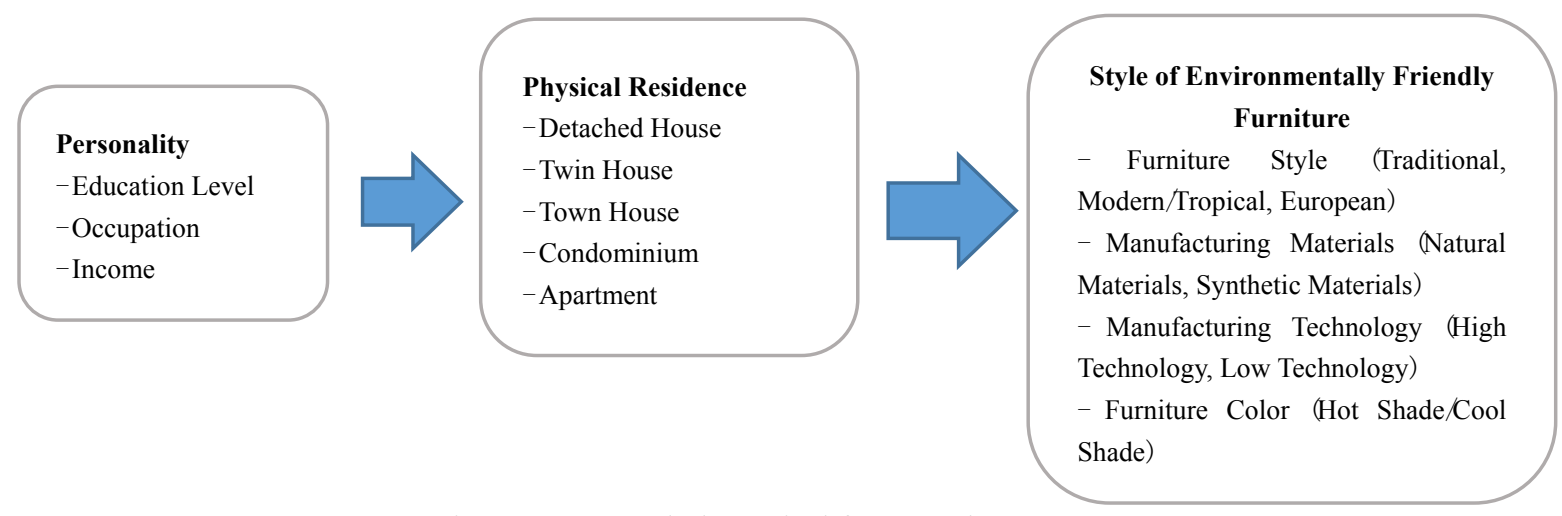

Figure 1. Research theoretical framework

The above figure shows the research hypothesis to find the cause of the rational between the independent variables and the dependent variables of the consumers. The independent variables are categorized into 2 groups as follows: 
1) Personality Variables mean the attribution in terms of education level, occupation, and income since these 3 variables can indicate the characteristic of consumer's socio-economic status.

2) Physical Residence Variables mean detached house, twin house, town house, condominium, and apartment. All these variables come from the consumer's personality.

\section{Research Methodology}

\subsection{Research Procedures}

This research has divided the research procedures into 4 main steps as follows:

Step 1: Choose the sample of furniture that will be used as the sample for other furniture in the study by survey all seven brands of furniture in Thailand, the brand names are classified into different categories. According to the use of the Each room has its own furniture. Table type is in the type of furniture used in each room found that the sample chose the table furniture which was used as the sample of furniture in the research.

Step 2: Build the experimental instrument by simulating the style of furniture in the table furniture that is designed by using the principles of environmentally friendly furniture design in the categories of furniture style (traditional, modern / Tropical, European), manufacturing materials (natural materials, synthetic materials), furniture manufacturing technology (high technology, low technology), and furniture color (hot shade, cool shade).

Step 3: Test the perception of furniture simulation style that is designed to serve as the instrument to collect the questionnaire from the sample.

Step 4 : Use the information from the questionnaire to do the statistical analysis to conclude the guideline of the needs for environmentally friendly furniture style of the sample that comes from different socio-economic conditions.

\subsection{Case selection}

Survey the furniture market in Bangkok. The furniture sold in the market is mainly used in the home. The furniture in the market is divided into two large groups of furniture in the home. And use outside. In this survey, we selected a company that sells furniture at the top level. Both domestic sales. Exports include imports. We have a wide range of products to choose from. We have 7 companies in our company. Winner mart group Co., Ltd, Modernform Group Co., Ltd., Podium Home center Co., Ltd., IKEA Thailand Co.Ltd., Used to survey the sample selection of this research. The researcher selects the group of furniture used in the house according to the characteristics of the use of furniture in five groups as follows. Furniture used in the bedroom, living room, dining room, kitchen, and office. Type of research sample The separation of furniture used in each room. The furniture in every room is a table, cabinet, but the research has limited time. Researchers chose table type furniture. This is used for the creation of research tools. To be appropriate for the time spent in research.

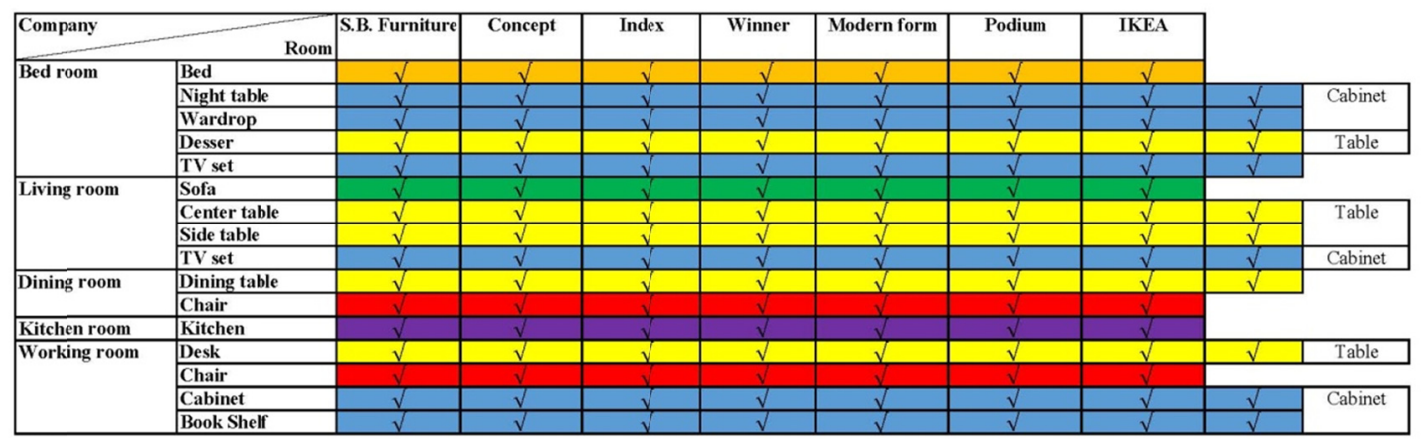

Figure 2. How to choose a case study

\subsection{Area selection}

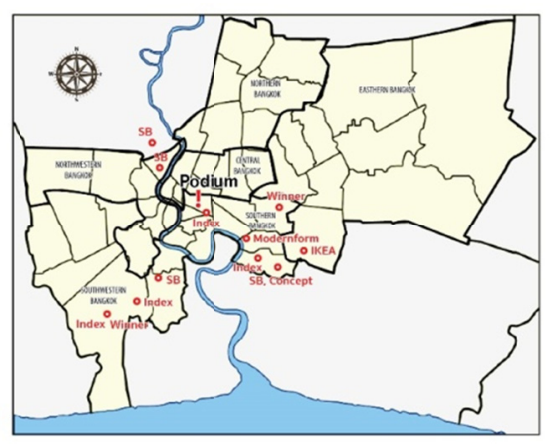

Figure 3. How to area selection for study 
The sampling for this research was chosen from a sample with the power to make buying decisions and to choose the furniture, which is the working group in Bangkok Metropolitan Region without separating the sample that is needed to collect the questionnaire. For the selection of venue to collect the questionnaire, since the researcher needed a sample that can represent the whole sample, questionnaire data was collected from furniture showrooms in the Bangkok Metropolitan Region, which were set up as private showrooms, for a total of 7 brands. Then, showrooms were chosen in the downtown area so that questionnaires could be collected to cover the customers with residences that meet the demand, furniture is sold in the showroom, such as furniture made of natural materials. Synthetic materials There are a variety of styles of furniture. Which were the showrooms of Podium Home Center Company, which is located in the heart of the city and representing a showroom that can sell furniture.

\subsection{Data Collection}

\subsubsection{Sampling Technique}

The sample for the questionnaire collection by using a picture model of the environmentally friendly furniture in various types according to the categories of the design for the environment was a working group of 100 people, by using volunteering questionnaire collection without dividing the sample into who buys the furniture and who does not buy the furniture, in order to acquire information from both buyers and non-buyers, using the instrument which created a picture model to be used in the questionnaire and separating the collection of questionnaire by 2 people at a time, to be able to take care of all the respondents thoroughly. The time used for collecting each questionnaire was 30 minutes for 10 respondents per day, using a total of 10 days to collect all questionnaires until complete.

\subsubsection{Research Methodology Tools}

An illustrative questionnaire was used to model the environmental friendliness of the samples. It is comparable with 5 levels of popularity.

\begin{tabular}{ccccccccccc}
\hline & \multicolumn{2}{c}{ Like the left-hand side } & equal & \multicolumn{3}{c}{ Like the right-hand side } \\
\hline 5 & 4 & 3 & 2 & 1 & 0 & 1 & 2 & 3 & 4 & 5 \\
\hline
\end{tabular}

Like the left-hand side select in the 1-5 number field on the left-hand side.

Like the right-hand side select in the 1-5 number field on the right-hand side.

Like both pictures are equal. Choose the 0 number.

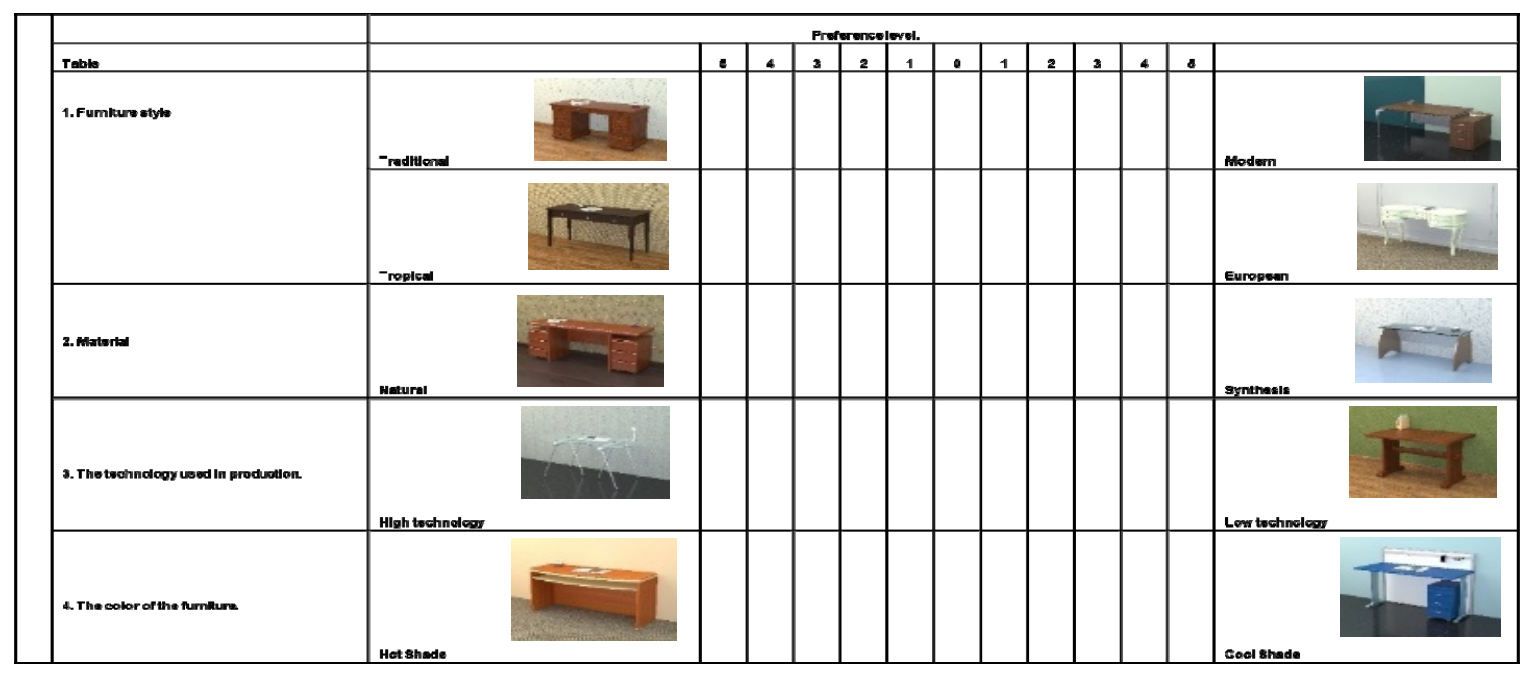

Figure 4. Methodology Tools

\section{Results}

4.1 The Characteristic Analysis of the Socio-Economics of the Sample

Table 2. Percentage and Number of Occupations, Categorized by Education Level

\begin{tabular}{cccccc}
\hline \multirow{2}{*}{ Education Level } & \multicolumn{4}{c}{ Occupation } & \multirow{2}{*}{ Percentage (Total) } \\
\cline { 2 - 4 } & Civil Service & Private Company & Self-Employed & Others & \\
\hline High School & $(0)$ & $83.3(5)$ & $(0)$ & $16.7(1)$ & $6.0(6)$ \\
Diploma & $29.4(5)$ & $58.8(10)$ & $11.8(2)$ & $(0)$ & $17.0(17)$ \\
Bachelor Degree & $12.7(7)$ & $38.2(21)$ & $49.1(27)$ & $(0)$ & $55.0(55)$ \\
Master Degree & $4.6(2)$ & $13.6(3)$ & $77.3(17)$ & $4.5(1)$ & $22.0(22)$ \\
\hline Percentage (Total) & $14.0(14)$ & $39.0(39)$ & $46.0(46)$ & $1.0(1)$ & $100(100)$ \\
\hline
\end{tabular}

$\mathrm{C}=40.09 \quad \mathrm{dtf}=9 \quad \mathrm{Sig}=.000$ 
The personality of the sample had a maximum education level of bachelor degree, followed by master degree, diploma, and a minimum of high school. When analyzing occupation and education (Table 2), it is found that self-employment is the highest in master degree and bachelor degree holders, followed by employees in private company, which shows that those who have a high education level will choose to be self-employed to relatively high degree. The test results by using Chi-square found that education level and occupation had a relationship at average levels with a confidence level of 0.01 within statistical significance.

\subsection{The Income and Type of Residence Analysis of the Sample}

For the socio-economic analysis of the sample, because the consumption of each individual depends on the income as the main factor by which income can clearly indicate the socio-economic condition of the sample, when testing the income with the selection of residence of the sample, it can be seen that the type of residence depends on the income of the sample. The type of residence is the determiner for the environmentally friendly furniture style of the sample. The income and type of residence are interrelated. According to the study of 100 samples, it is found that the samples who reside in a town house have the highest average income of 32,925 baht per month, followed by detached house with an average income of 32,487 baht per month, and apartment with the lowest average income of 15,250 baht per month. Detached house, twin house, and town house are the types of residences that have a high price. Therefore, the sample who resides in these residences will have high income with a confidence level of 0.01 within statistical significance.

Table 3. Average Income per Month, Categorized from the Type of Residence of the Sample

\begin{tabular}{|c|c|c|c|c|c|c|}
\hline \multirow{2}{*}{ Average Income } & \multicolumn{5}{|c|}{ Type of Residence } & \multirow{2}{*}{ Average } \\
\hline & Detached House & Twin House & Town House & Condominium & Apartment & \\
\hline Average Income per Month & 32,487 Baht & 27,571 Baht & $32,925 \mathrm{Baht}$ & 23,562 Baht & $15,250 \mathrm{Baht}$ & 29,800 Baht \\
\hline
\end{tabular}

The environmentally friendly furniture design analysis of the sample and corresponding to the socio-economics of the sample with different education by comparing mean and testing the relationship by using Linear Regression found that all education level groups tend to have demands for environmentally friendly furniture design in the same direction. However, the master degree group had a distinctly higher demand for modern furniture style than other education groups, and were also able to describe the demand in various aspects of the sample with a confidence level of $95 \%$ within statistical significance as shown in Figure 5.

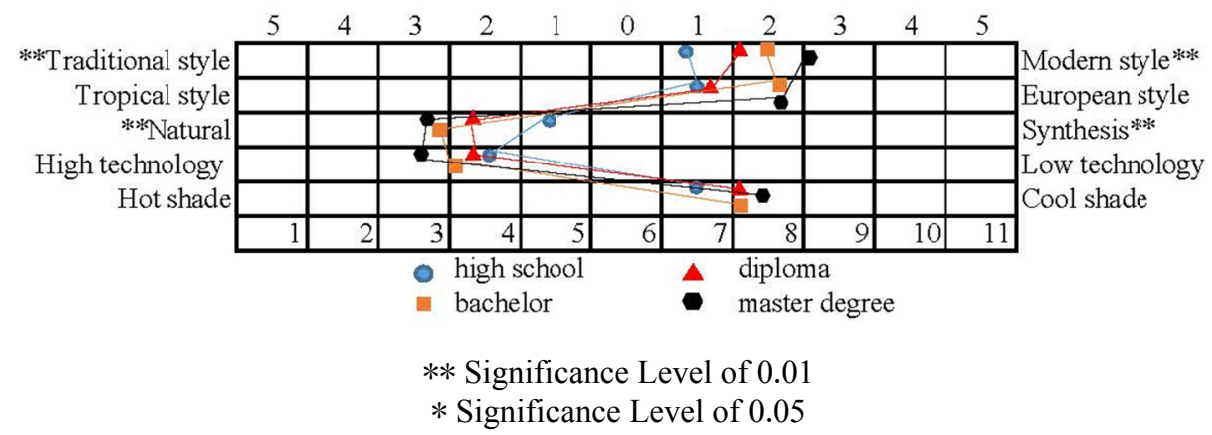

Figure 5. The demand for environmentally friendly furniture of the sample with different education levels

Table 4. The Relationship of Education Level with Demand for Environmentally Friendly Furniture Style of the Sample

\begin{tabular}{cccccc}
\hline Dependent Variable & Independent variables & r. & $\mathrm{r}^{2}$ & B (Beta) & P (Sig.) \\
\hline Furniture style Traditional / Modern & Education & $.482^{\mathrm{a}}$ & .224 & .397 & .000 \\
Material Natural / synthesis & Education & $.601^{\mathrm{b}}$ & .348 & -.369 & .006 \\
\hline
\end{tabular}

\subsection{Occupation Analysis and Demand for Environmentally Friendly Furniture Style of the Sample}

Occupation is very important at present because it can indicate the expertise of a person in many aspects. Occupation also can generate income and indicate the socio-economic background of the sample. According to the study of demand for furniture style of the sample with different occupations, which were civil service, employees in private company, self-employed, and others, by using Compare mean and testing the relationship by using Linear Regression, it was found that occupation was able to describe the relationship of the demand for environmentally friendly furniture style in Tropical and European style for only one category (Table 5), but the demand in other categories were in the same direction as shown in Figure 6. 


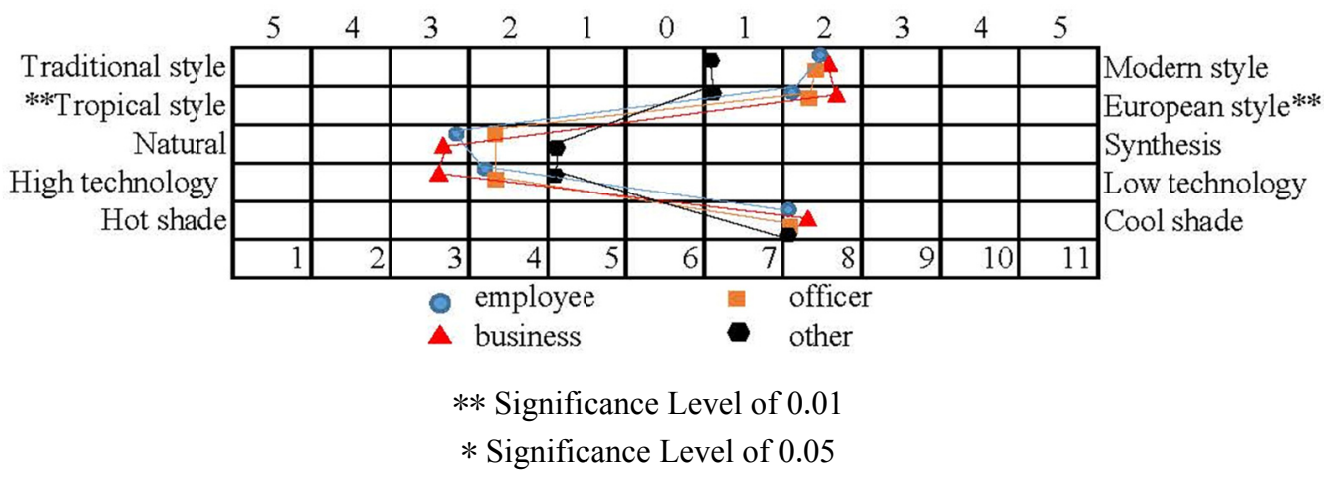

Figure 6. Relationship of Occupation and Demand for Environmentally Friendly Furniture Style of the Sample

Table 5. Relationship of Occupation and Demand for Environmentally Friendly Furniture Style of the Sample

\begin{tabular}{cccccc}
\hline Dependent Variable & Independent variables & r. & $\mathrm{r}^{2}$ & $\mathrm{~B}(\mathrm{Beta})$ & $\mathrm{P}($ Sig.) \\
\hline Furniture style Tropical / European & Occupation & $.261^{\mathrm{a}}$ & .058 & .261 & .009 \\
\hline
\end{tabular}

\subsection{The Analysis of Income and Demand for Environmentally Friendly Furniture Style of the Sample}

The consumption of the sample depends on many factors by which income is the main factor of the socio-economic backgrounds of the sample. Those with high income will have an opportunity to buy high-quality products. From 100 samples, the income can be categorized into 3 groups and relationships were found by using Linear Regression. It was found that income is related to the demand for environmentally friendly furniture design in the same direction, except for the category of manufacturing materials and manufacturing technology. Income was able to describe the demand for the furniture style with a confidence level of $95 \%$ within statistical significance as shown in Table 6.

Table 6. Relationship of Income and Demand for Environmentally Friendly Furniture Style of the Sample

\begin{tabular}{cccccc}
\hline Dependent Variable & Independent variables & r. & $\mathrm{r}^{2}$ & B (Beta) & P (Sig.) \\
\hline Material Natural / synthesis & Income & $.419^{\mathrm{a}}$ & .168 & -.263 & $.000^{\mathrm{a}}$ \\
Technology in process High technology / Low technology & Income & $.460^{\mathrm{b}}$ & .195 & -.245 & $.000^{\mathrm{b}}$ \\
\hline
\end{tabular}

\subsection{The Analysis of Physical Residence and Demand for Environmentally Furniture Style of the Sample}

Physical residence is one of the factors that indicates the demand for environmentally friendly furniture style of the sample since residence is a result of the socio-economic background of the sample. Therefore, different residences have different demands for environmentally friendly furniture style. The environmentally friendly furniture style can be analyzed from the types of residence, which are categorized into detached house, town house, condominium, apartment, and twin house by using compare mean and testing the relationship by using Linear Regression. It is found that the types of residence was able to describe the demand for traditional style and modern style and manufacturing materials for environmentally friendly furniture of the sample in the same direction as shown in Figure 7.

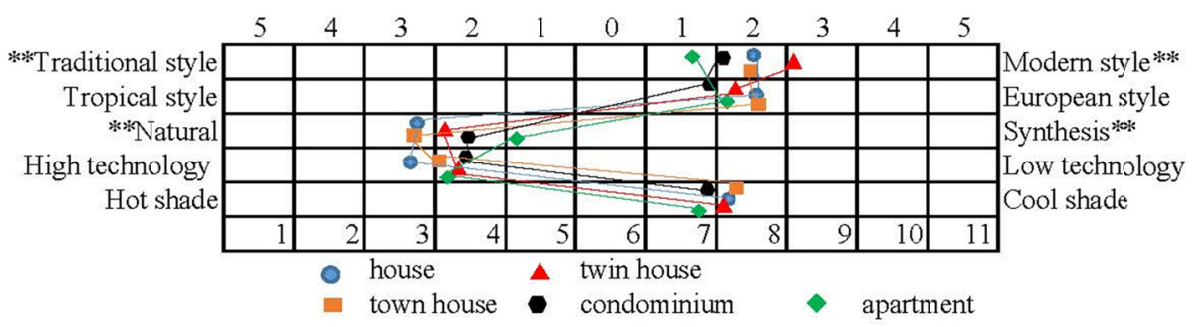

** Significance Level of 0.01

* Significance Level of 0.05

Figure 7. The Demand for Environmentally Friendly Furniture Style of the Sample with Different Residence

Table 7. The Analysis Results of the Types of Residence and Demand for Environmentally Friendly Furniture Style of the Sample

\begin{tabular}{cccccc}
\hline Dependent Variable & Independent variables & r. & $\mathrm{r}^{2}$ & B (Beta) & P (Sig.) \\
\hline Furniture style Traditional / Modern & House & $.277^{\mathrm{a}}$ & .068 & -.232 & $.005^{\mathrm{a}}$ \\
Material Natural / synthesis & House & $.337^{\mathrm{a}}$ & .095 & .197 & $.003^{\mathrm{a}}$ \\
\hline
\end{tabular}


It can be seen that the relationship of each independent variable is related with the demand for furniture style, materials, and the technology in the manufacturing in each relationship. Therefore, the furniture manufacturing materials and the manufacturing technology is important for the environmentally friendly furniture design guideline.

\section{Discussion and Recommendations}

An environmentally friendly design that responds to the demands of the consumer's furniture style is a key principle for designers and furniture entrepreneurs that will determine good sales performance. The characteristics of the socio-economic background of the target group sets the demands for the furniture style in which those who have the potential to buy and make a decision are satisfied with the environmentally friendly furniture style.

\subsection{Environmentally Friendly Furniture Design Guideline with the Demand of the Target Group for Designers to use} as a Design Guideline

1) Environmentally friendly furniture design in modern style more than traditional style and western style over eastern style, which is popular with current times. Furniture that is modern and emphasizes style more. The types of residences are modern and western style and so residential projects have increasingly followed this same design. Designers should consider the overall habitat of the target audience or target audience. Before designing furniture to achieve the style of furniture that is environmentally friendly to meet the needs of the target.

2) For the manufacturing materials, the target group has the demand for environmentally friendly furniture that uses natural materials in the manufacturing since domestic manufacturers turn to using more natural materials in the manufacturing, such as rubber wood and rattan. Environmentally friendly furniture that is made from natural materials provides liveliness for the residents. The designer selects materials for production. It should be natural materials from the forest. With sustainable management Avoid toxic materials with toxic substances. Especially attention to reducing the use of urea formaldehyde. Recycled materials can be recycled after use.

3) For the manufacturing technology, the target group has the demand for environmentally friendly furniture that uses high technology in the manufacturing. Which is essential for the production of furniture. Technology and machinery should be maintained so that quality and efficient furniture can be produced. Reduce energy consumption And reduce the waste of parts. Entrepreneurs have brought machinery in the manufacturing to produce higher amount of furniture in the industry so that the price of environmentally friendly furniture is not too high and lifespan of the furniture is able to be determined.

4) For the environmentally friendly furniture's color, the target group has the demand for the furniture to have a cool shade since the target group sees that it provides a comfortable feeling for the user and the residents. Designers need to focus on the use of non-toxic paint and surfaces that release chemicals into the atmosphere.

\subsection{Recommendations}

\subsubsection{Recommendation for applying research results}

From the study of the differentiation of the sample with socio-economic conditions as the key variable but uncontrollable, the design for the environmentally friendly furniture to meet the market demands is relatively difficult. Therefore, the designer must design environmentally friendly furniture according to the selling demands more than designing furniture for all groups. The socio-economic status of the sample is the income of the sample. It determines the residence and life style.

\subsubsection{Recommendations for further research}

In this research, there might be some things that can benefit the design but still with some limitations. Therefore, the researcher provides suggestions to focus on to make the study more complete.

For further research, there should be a reliability test for the instrument before actual use.

This research cannot do the experiment for all rooms and all types of furniture since the furniture model might be unpractical and there are many types of furniture in the house. Therefore, further research should research all types of furniture to be more complete.

This research is a study for the demand of environmentally friendly furniture style by using illustrations.

However, in reality, the illustrations cannot make the sample envision other furniture environments. Therefore, the illustrations should be controlled to cover more furniture.

\section{Acknowledgements}

The author would like to thank Assoc. Prof. Dr. Nopadon Sahachaisaeree and Asst. Prof. Dr. Yanin Rugwongwan, Faculty of Architecture, King Mongkut's Institute of Technology Ladkrabang, Thailand, and Dr. Wichitra Singhirunnusorn for their kind suggestions, guidance, and support to the researcher.

\section{References}

Araji, M. T., \& Shakour, S. A. (2013). Realizing the environmental impact of soft materials: Criteria for utilization and design specification. Materials \& Design, 43, 560-571. doi:org/10.1016/j.matdes.2012.07.053

Brezet, H., \& Hemel, v. C. (1997). Ecodesign : a promising approach to sustainable production and consumption. Paris, France : United Nations Environment Programme, Industry and Environment, Cleaner Production ; The 
Hague : Rathenau Institute ; Delft, Netherlands : Delft University of Technology, C1997.

Brown, B. J., Hanson, M. E., Liverman , D. M., \& Merideth Jr., R. W. (1987, November ). Global sustainability: Toward definition. Environmental Management, 11(6), 713-719. doi:doi.org/10.1007/BF01867238

Chiu, M.-C., \& Chu, C.-H. (2012, July). Review of sustainable product design from life cycle perspectives. International Journal of Precision Engineering and Manufacturing, 13(7), 1259-1272. doi:doi.org/10.1007/s12541-012-0169-1

COLE, M. A., ELLiOTT, R. J., \& WU, S. (2008, September ). Industrial activity and the environment in China: An industry-level analysis. China Economic Review, 19(3), 393-408. doi:doi.org/10.1016/j.chieco.2007.10.003

Consultants of Technology Co., L. (2556, March). 30 years 2526-2556. Retrieved from Consultants of Technology Co., LTD.:

http://www.cot.co.th/home/index.php/th/general-news-issue/27-business-economic-management/540-green-consu mer.html

Durmaz, Y., \& Yasar, H. V. (2016). Green Marketing and Benefits to Business. Business and Management Studies, 2(2), 64-71. doi:10.11114/bms.v2i2.1624

Hayles, C. S. (2015, June). Environmentally sustainable interior design: A snapshot of current supply of and demand for green, sustainable or Fair Trade products for interior design practice. International Journal of Sustainable Built Environment, 4(1), 100-108. doi:doi.org/10.1016/j.ijsbe.2015.03.006

Lewis, H., Gertsakis, J., Grant, T., Morelli, N., \& Sweatman, A. (2001). Design+Environment a global guide to designing greener goods. Sheffield, UK: Greenleaf Publishing Limited.

SMEs. (2014). SMEs High Growth Sectors. Bangkok: SMEs White paper 2014.

Tcdc. (2017, september 6-21). Work shop "Eco-Creator". Retrieved from Tcdc.or.th: www.tcdc.or.th

Telenko, C., Seepersad, C. C., \& Webber, M. E. (2008). A Compilation of Design for Environment Principles and Guidelines. ASME 2008 International Design Engineering Technical Conferences and Computers and Information in Engineering Conference, 5, pp. 289-301. Brooklyn, New York,. doi:10.1115/DETC2008-49651

Thailandindustry. (2009, 06 17). Green Procurement Purchasing eco-friendly products. Retrieved from Thailandindustry: http:/www.Thailandindustry.com/guru/view.php?id=7445\&section=9

Zhang, O. M., \& Zhang, W. M. (2012, December ). Material Election and Ecological Design for Furniture Products Based on the Principles of Green Manufacturing. Advanced Materials Research (Volumes 610-613), pp. 502-506. doi:10.4028/www.scientific.net/AMR.610-613.502

\section{Copyrights}

Copyright for this article is retained by the author(s), with first publication rights granted to the journal.

This is an open-access article distributed under the terms and conditions of the Creative Commons Attribution license (http://creativecommons.org/licenses/by/4.0/). 